\title{
置換度の異なるトリチルセルロースの誘電特性
}

\author{
東京農工大学 佐渡 篤, 山田俊次, 高島藤順

\section{Dielectric Properties of Tritylcellulose with various Degree of Substitution}

\author{
Atsushi Sawatari, Toshitsugu Yamada and Tohjun Takashima \\ Tokyo University of Agriculture and Technology
}

\begin{abstract}
In regard to cellulose, the frequency dispersion of dielectric loss factor or dielectric loss tangent are generally observed at about $-60^{\circ} \mathrm{C}$ over the range of frequency from $30 \mathrm{~Hz}$ to $1 \mathrm{MHz}$. According to Mikhailov et $\mathrm{al}^{13,2)}$ and Norimoto $\mathrm{et}^{\mathrm{a} 1^{3,5}}{ }^{3}$, this dispersion is interpreted as the relaxation originated in $\mathrm{CH}_{2} \mathrm{OH}$ group of glucose residue in the amorphous region.

In this paper, triphenylmethylcellulose (tritylcellulose) were prepared with the various degree of substitution (D. S.). In order to confirm the above mentioned interpretation and further to find the dispersion change with the decrease of $\mathrm{CH}_{2} \mathrm{OH}$ group, the dispersion of the prepared tritylcellulose with various D. S. were measured at $-59^{\circ} \mathrm{C}$, from $300 \mathrm{~Hz}$ to $300 \mathrm{kHz}$. The same experiments were carried out for some cellulose acetates with various D.S.. The following results were obtained in common between tritylcellulose and cellulose acetate:
\end{abstract}

i). With the increase of D.S., the height of the dispersion decreased.

The observed phenomenon suggests that the height of the dispersion is determined by the quantity of unsubstituted $\mathrm{CH}_{2} \mathrm{OH}$ group.

ii) The linear relation was observed between the height of the dispersion and the quantity of $\mathrm{CH}_{2} \mathrm{OH}$ group per specimen volume. Moreover, the slope of the straight line were almost equal for the two derivatives used. Therefore, the essential factor determined the height of the dispersion is considered to be quantity of $\mathrm{CH}_{2} \mathrm{OH}$ group per specimen volume.

From the results i) and ii), the relaxation mechanism of this dispersion is considered to be related to a motion of $\mathrm{CH}_{2} \mathrm{OH}$ group of glucose residue in the amorphous region.

\section{1. 緒言}

セルロース系物質について $-60^{\circ} \mathrm{C}$ 付近の低温に観 測される $30 \mathrm{~Hz}$ から $1 \mathrm{MHz}$ にわたる誘電損率また は誘電正接の周波数分散は, Mikhailov らの研究によ り非結晶領域中のグルコース残基の $\mathrm{CH}_{2} \mathrm{OH}$ 基（第 一級アルコール基) が関与していることが判明してい る $^{1), 2)}$ 。

則元らは，この分散がセルロースとコンニャクマン ナンに見出され，キシランに認められないことから ${ }^{3)}$, Mikhailov らの見解を支持し，さらにこの緩和機構の 活性化エネルギーが 8.5 10.2 (kcal/mol) の大きさ であること並びにこの值が $\mathrm{Zhbankov}^{4}$ ) のポテンシャ
ル壁の高さと一致することから，この分散が $\mathrm{C}_{5}-\mathrm{C}_{6}$ 軸のまわりの第一級アルコール基の $\mathrm{OH}$ 双極子の回 転運動の緩和機構に基づいていると帰属した ${ }^{5)}$ 。 このたび筆者らは, この分散が $\mathrm{CH}_{2} \mathrm{OH}$ 基に依っ ていることをセルロース誘導体の立場から確認するた めに，そしてさらに，グルコース残基中! $\mathrm{CH}_{2} \mathrm{OH}$ 基の量を変化させたときのこの分散の変化を実験的に 見出すために, $\mathrm{CH}_{2} \mathrm{OH}$ 基が選択的に置換されるトリ フェニルメチルセルロース（トリチルセルロース）を 種々の置換度に調製し，その低温域における誘電損率 の周波数分散を調べた。また，アセチルセルロースに ついても同様の検討を行なったので併せてその結果を 述べる。筆者らは, 種々の叨解度のパルプから得られ 
るシートについでこの分散を倹索中である ${ }^{6}$ のでそ の前報として報告する。

\section{2. 実験}

\section{1 種々の置換度のトリチルセルロースの調製}

トリチルセルロースの調製は, Green の記述した 方法”によった。以下にその方法を具体的に述べる。

アセチルセルロースを完全に䲓化して得を再生セル ロース粉末 $10 \mathrm{~g}$ を $50 \%$ ピリジン水溶液 $200 \mathrm{~m} l$ 中に 浸漬し, 湯煎上で 1 時間加熱し, 沪別後, 残查のセル ロースを脱水ピリジン $200 \mathrm{~m} l$ と共に擋拌しながら 1 時間加熱する。脱水ピリジンによるこの操作を 3 回繰 り返した後, 残査セルロースに脱水ピリシシン $170 \mathrm{~m} l$ とトリフェニルクロロメタン $40 \mathrm{~g}$ を加え, 16 時間激 しく擋拌しながら湯煎上で加熱する。その結果得られ た透明な暗かっ色の溶液を沪過し，メタノール中に注 ぐことによって沈殿させる。沈殿したトリチルセルロ 一スを精製するために再度ピリジンに溶解して, メ夕 ノール中に添加し沪別する。

こらして得られたトリチル置換度 ${ }^{8)}$ は，1.091 であ った。得られた粉末の赤外吸収スペクトルが Zhbankov らのそれ帛と一致したので, トリチルセルロース が調製できたと判断した。また，反応時間を短縮する ことによって, より小さい置換度のトリチルセルロー スを得た。反応時間と得られたトリチルセルロースの 置換度 (D.S. T と略記) との関係を Fig.1 亿示す。

\section{2 種々の置換度のアセチルセルロースの調製}

置換度 2.49 の市販アセチルセルロース $10 \mathrm{~g}$ を, 28 \%アンモニア水 $100 \mathrm{~m} l$ で 0 9 時間噓化処理して各 置換度のアセチルセルロースを得た。畧化時間と得ら れたアセチルセルロースのアセチル置換度の関係を

Fig. 2 に示す。

アセチル化されていない $\mathrm{CH}_{2} \mathrm{OH}$ 基の定量は $\mathrm{Ta}-$ nghe らのトリチル化法 (重量法) $\left.{ }^{10}\right)$ に従って定量し た。

\section{3 誘電損率の周波数分散の測定}

\section{3 .1 誘電測定用試料の調製}

2.1 と 2.2 で得られた各セルロース誘導体の粉末を 真空乾焼後, 成型器によって $150\left(\mathrm{~kg} / \mathrm{cm}^{2}\right)$ の圧力で 5 分間圧締して誘電測定用試料を得た。この円板状の 試料を五酸化りんを入れたデシケータ中で, 約 20 時 間 $3 \times 10^{-2}$ Torr の真空度で乾焼した後測定に付した。

\section{3 .2 測定}

誘電損率の周波数分散の測定は, 安藤電気 (秼) 製の WBG-3B 型発振器, TR-1B 型ブリッジ, BDA-1 $\mathrm{B}$ 型平衡点検出器, $\mathrm{SE}-3$ 型恒温槽付電極の組み合せ

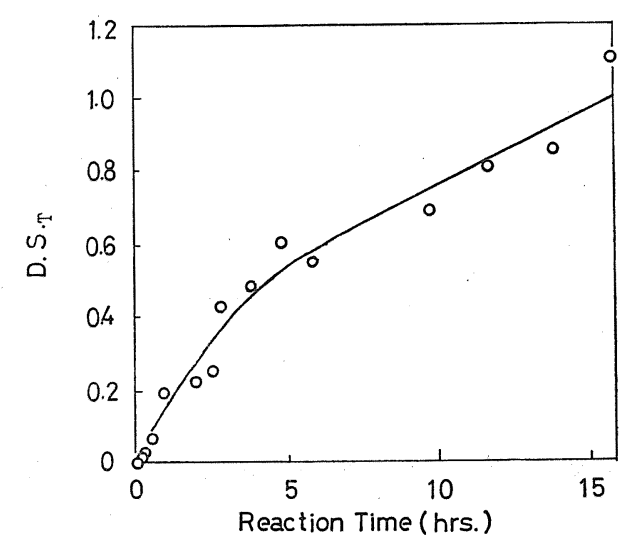

Fig. 1 Trityl D.S. of tritylcellulose (D.S.T) vs. reaction time

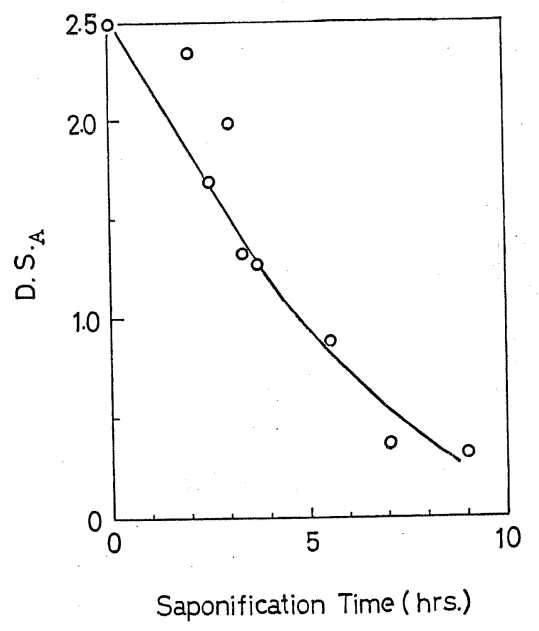

Fig. 2 Acetyl D.S. of collulose acetate (D.S.A) vs. saponification time

を用いておこなった。恒温槽中に五酸化りんを入れ， ドライアイスを寒剤として周囲より冷却し $-60^{\circ} \mathrm{C}$ と した後, 温度制御して測定した。

\section{3. 結果と考察}

得られたセルロース誘導体の誘電損率 $\left(\varepsilon^{\prime \prime}\right)$ の周波 数分散をトリチルセルロースについて Fig. 3 に, ア セチルセルロースについて Fig. 4 亿示す。

得られた周波数分散の極大值に近い $10 \mathrm{kHz}$ におけ る誘電損率の值 $\left(\varepsilon^{\prime \prime}{ }_{10 \mathrm{KHz}}\right)$ を各置換度 (D.S.) に対 してプロットし Fig. 5 に, $\mathrm{CH}_{2} \mathrm{OH}$ 基における置換 度 (D.S..$_{1}$ ) に対してプロットして Fig. 6 に示す。

Fig. 5 から，この二つのセルロース誘導体に共通 して, 置換度の増大に伴って分散の高さが低くなるこ 


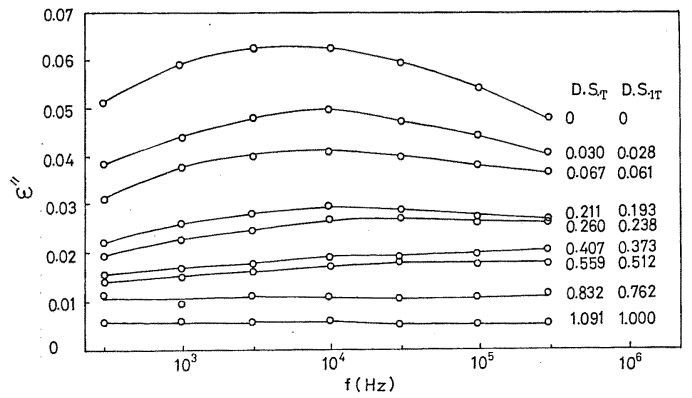

Fig. 3 Frequency dispersion of dielectric loss factor $\left(\varepsilon^{\prime \prime}\right)$ in regard to tritylcellulose with various D.S. at $-59^{\circ}$ C. D.S.T : Trityl D.S., D.S.1T : Trityl D.S. at $\mathrm{CH}_{2} \mathrm{OH}$ group

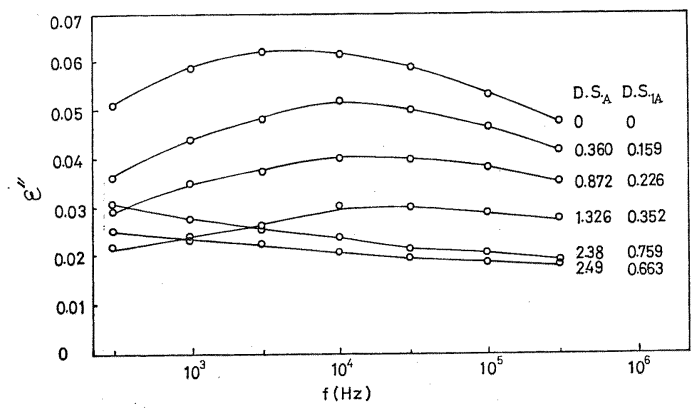

Fig. 4 Frequency dispersion of dielectric loss factor $\left(\varepsilon^{\prime \prime}\right)$ in regard to cellulose acetate with various D.S. at $-59^{\circ} \mathrm{C}$. D. $\mathrm{S}_{\mathrm{A}}$ : Acetyl D.S., D.S. ${ }_{1 \mathrm{~A}}$ : Acetyl D. S. at $\mathrm{CH}_{2} \mathrm{OH}$ group

とが認められる。さらに, Fig. 6 から $\mathrm{CH}_{2} \mathrm{OH}$ 基に おける置換度 (D. S. ${ }_{1}$ ) の增大に伴って分散の高さが 低くなることが認められる。このことから， $\mathrm{CH}_{2} \mathrm{OH}$ 基がふさがれることによって分散が消失していく傾向 が確認できる。したがって Mikhailov らや則元らの 述べるように，この分散が $\mathrm{CH}_{2} \mathrm{OH}$ 基に媲因してい るとする結論がセルロース誘導体を用いた本研究によ っても支持されたと考えられる。

つぎに，ここで得られた結果を緩和機構の量，すな わち $\mathrm{CH}_{2} \mathrm{OH}$ 基の量に着目して整理することとする。

則元ら ${ }^{11)}$ は, 比重の異なった木材の繊維方向につい てこの分散の高さを求め, 比重との間に比例関係があ ることを見出した。この現象から，分散の高さは単位 体積あたりの緩和機構の量, すなわち $\mathrm{CH}_{2} \mathrm{OH}$ 基の 量に比例していると考えることができる。
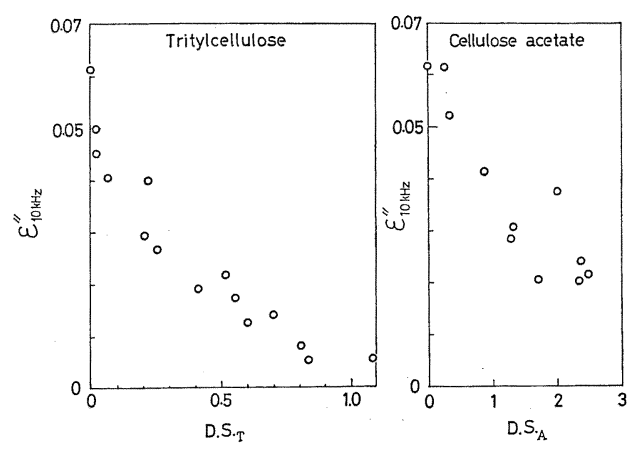

Fig. 5 Dielectric loss factor at $10 \mathrm{kHz}$ $\left(\varepsilon^{\prime \prime}{ }_{10 \mathrm{kHz}}\right)$ vs. D.S. D.S.T : Trityl D.S., D.S.A : Acetyl D.S. $\varepsilon^{\prime \prime}{ }_{10 \mathrm{kHz}}$ $=-0.04401$ D.S.T $+0.04606(r=$ $-0.9101), \quad \varepsilon^{\prime \prime}{ }_{10 \mathrm{kHz}}=-0.01606$ D.S.A $+0.05823(r=-0.8992)$
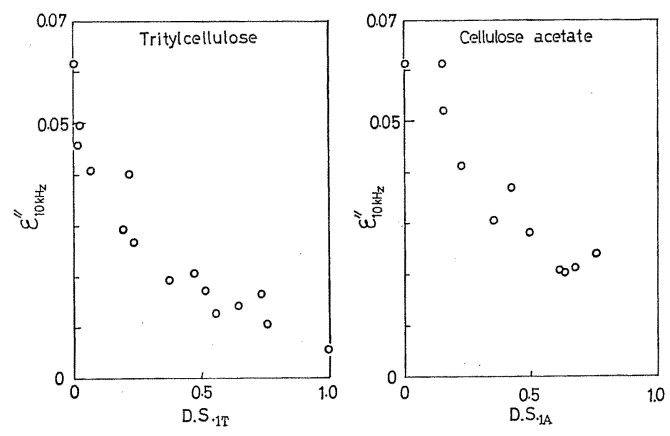

Fig. 6 Dielectric loss factor at $10 \mathrm{kHz}$ $\left(\varepsilon^{\prime \prime}{ }_{10 \mathrm{kHz}}\right)$ vs. D.S. at $\mathrm{CH}_{2} \mathrm{OH}$ group. D.S. ${ }_{1 T}$ : Trityl D.S. at $\mathrm{CH}_{2}$ $\mathrm{OH}$ group., D.S.1A : Acetyl D.S. at $\mathrm{CH}_{2} \mathrm{OH}$ group, $\quad \varepsilon^{\prime \prime}{ }_{10 \mathrm{kHz}}=-$ 0.4802 D.S. ${ }_{1} \mathrm{~T}+0.04606(r=-0$. 9101), $\quad \varepsilon^{\prime \prime}{ }_{10 \mathrm{kHz}}=-0.05965$ D.S. ${ }_{1 \mathrm{~A}}$ $+0.06059(r=-0.9344)$

したがって，この考えを本研究で得られた結果に適 用してみることとする。すなわち，単位体積あたりの $\mathrm{CH}_{2} \mathrm{OH}$ 基のモル数 $n_{1}$ を算出して, 分散の高さ $\varepsilon^{\prime \prime}{ }_{10 \mathrm{KH} z}$ を $n_{1}$ に対してプロットする。

トリチルセルロースに関しては，トリチル化度 T\% と $\mathrm{CH}_{2} \mathrm{OH}$ 基におけるトリチル置換度 D. S..$_{1 \mathrm{~T}}$ *およ び誘電測定用試料の比重 $r$ を用いて $1 \mathrm{~cm}^{3}$ あたりの $\mathrm{CH}_{2} \mathrm{OH}$ 基のモル数 $n_{1 \mathrm{~T}}$ を求めると, $n_{1 \mathrm{~T}}=(r / 162)$ ・ $(1-\mathrm{T} / 100) \cdot\left(1-\mathrm{D} . \mathrm{S} \cdot{ }_{1 \mathrm{~T}}\right) \mathrm{Mol} \cdot \mathrm{cm}^{-3}$ となるので, こ の值に対して分散の高さ $\varepsilon^{\prime \prime}{ }_{10 \mathrm{KHz}}$ をプロットする

* 注 1 D.S. . $_{\mathrm{T}}=$ D.S.T. $/ 1.091$ として計算した。 


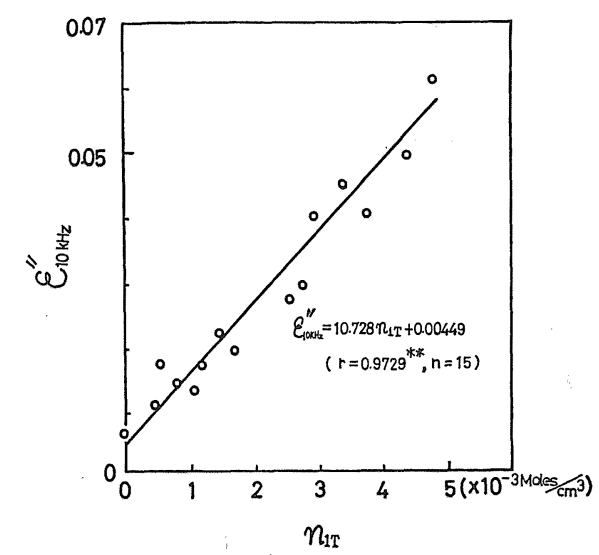

Fig. 7 Dielectric loss factor at $10 \mathrm{kHz}\left(\varepsilon^{\prime \prime}{ }_{10}\right.$ $\mathrm{kHz}$ ) vs. moles of unsubstituted $\mathrm{CH}_{2}$ $\mathrm{OH}$ group per specimen volume of tritylcellulose $\left(n_{1 \mathrm{~T}}\right)$

(Fig. 7)。

この結果，直線関係が認められ，かつ相関係数も

Fig. 6 の場合に比べて大きくなっている。

アセチルセルロースに関しても同様に, 単位体積中 に置換されずに残っている $\mathrm{CH}_{2} \mathrm{OH}$ 基のモル数 $n_{1 \mathrm{~A}}$ をアセチル化度 $\mathrm{A} \%, \mathrm{CH}_{2} \mathrm{OH}$ 基におけるアセチル置 換度 D.S. ${ }_{1 \mathrm{~A}}$ *** 号,$n_{1 \mathrm{~A}}=(r / 162) \cdot(1-\mathrm{A} / 100) \cdot(1-$ D.S. $\left.{ }_{1 \mathrm{~A}}\right) \mathrm{Mol} \cdot \mathrm{cm}^{-3}$ と算出して, この值に対して分散 の高さ $\varepsilon^{\prime \prime}{ }_{10 \mathrm{KHz}}$ をプロットした（Fig. 8)。

この場合も, Fig. 6 の場合に比べて相関係数は大 きくなっている。

Fig. 1，Fig.8から，トリチルセルロースとアセチ ルセルロースに共通して直線関係が認められ, その直 線のこう配はトリチルセルロースについて $10.7 \times 10^{-3}$ $\left(\mathrm{Mol}^{-1} \cdot \mathrm{cm}^{3}\right)$ ， アセチルセルロースについて $10.9 \times$ $10^{-3}\left(\mathrm{Mol}^{-1} \cdot \mathrm{cm}^{3}\right)$ と近い值を示した。このことからも， 残っている $\mathrm{CH}_{2} \mathrm{OH}$ 基の量が分散の高さを決める本 質的な要因であることが判る。Fig. 7 と Fig. 8 の切 片の值はトリチルセルロースとアセチルセルロースで 異なっているが, このことは $\mathrm{CH}_{2} \mathrm{OH}$ 基の $\mathrm{OH}$ 双極 子以外の置換によって導入された双極子に基づく分散 のすそ野によっていると思われる。そのことは,

Fig. 4 においてアセチル置換度が 2.38 以上の場合， 低周波側の誘電損率の值が大きくなっていることから も推察できる。

* 注 2 2.2において述べたトリチル化法による定 量值から求めた。

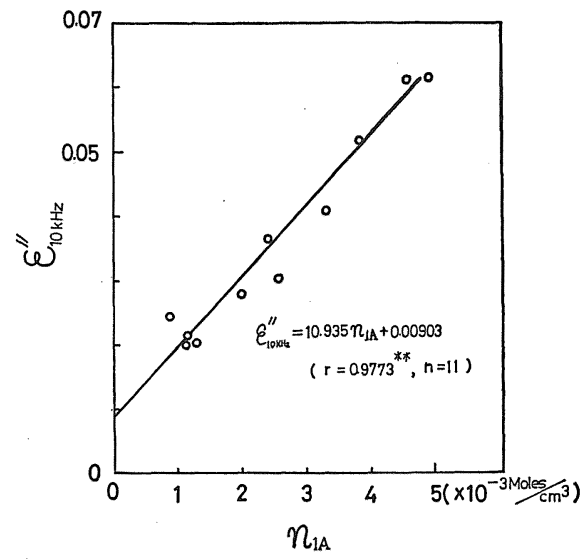

Fig. 8 Dielectric loss factor at $10 \mathrm{kHz}\left(\varepsilon^{\prime \prime}{ }_{10}\right.$ $\mathbf{k H z}$ ) vs. moles of unsubstituted $\mathrm{CH}_{2}$ $\mathrm{OH}$ group per specimen volume of cellulose acetate $\left(n_{1 \mathrm{~A}}\right)$

\section{4. 総括}

トリチルセルロース並びにアセチルセルロースを種 々の置換度に調製し,それらの誘電損率の $300 \mathrm{~Hz}$ から $300 \mathrm{kHz}$ にわたる周波数分散をー $59^{\circ} \mathrm{C}$ において求めた ところ，二つの誘導体に共通して以下の結果を得た。

i ), 置換度の増加に伴って, 分散の高さは低くな った。このことは, 置換されずに残っている $\mathrm{CH}_{2}$ $\mathrm{OH}$ 基の量が少なくなると，分散の高さが低く観測 されたことを示しているので，従来の考え方を支持 しているものと考えられる。

ii), 分散の高さは, 試料の単位体積あたりの置換 されずに残っている $\mathrm{CH}_{2} \mathrm{OH}$ 基の量によって直線 的に変化し，その直線のこう配はトリチルセルロー スとアセチルセルロースについてほぼ等しいことが 認められた。このことは, 分散の高さを決める本質 的な要因が単位体積あたりの $\mathrm{CH}_{2} \mathrm{OH}$ 基の量である ことを示唆しているものと思われる。

i)，ii）より $\mathrm{CH}_{2} \mathrm{OH}$ 基がこの分散の緩和機構に関与 していると考えられる。

\section{謝 辞}

本研究をおこなうにあたり種々御助言を頂いた京都 大学木材研究所 則元 京博士ならびに東京農工大学 伏谷賢美助教授に厚く御礼申し上げます。

（本研究の一部は, 1973年 4 月の第23回日本木材学会大会において発 表した。) 


$$
\text { 文献 }
$$

1) G.P.Mikhailov, A.I.Arthyukhov and V.A. Shevelev; Polymer Sci. U.S.S.R., 11, 628 (1969)

2) G.P.Mikhailov, A.I.Arthyukhov and T.I.Borisova; Vysokomolek. Soed., 8,138 (1966)

3) M.Norimoto and T.Yamada; Wood Research., No. 52, 31 (1972)

4) R.G.Zhbankov., Polymer Sci. U.S.S.R., 8, 1962 (1966)

5). M.Norimoto and T.Yamada; Wood Research., No. 46, 1 (1969), M.Norimoto and T.Y amada; Wood Research., 51, 12 (1971), M. Norimoto and T.Yamada; J.Japan. Wood. Res., 16, 364 (1970)
6) A.Sawatari and T.Takashima; The 22 th Annual Meeting of Japan. Wood. Res. Soc., (1972. Apr.)

7) J.W.Green; Methods in Carbohydrate Chemistry III. p.327 Academic Press, N. Y.(1963)

8) J.W.Green; Ibid p. 330

9) R.G. Zhbankov; Infrared Spectra of Cellulose and Its Derivatives., p.254 Consultants Bureau. A division of Plenum Pub. Corp., N. Y. (1966)

10) L.J.Tanghe; Methods in Carbohydrate Chemistry. III. p. 208, Academic Press. N.Y. (1963)

11) M.Norimoto and T.Yamada; J.Japan. Wood. Res. Soc., 16, 364 (1970) 